\title{
Primary breast lymphoma: a case report
}

\section{Hafsa Taheri*, Asma Hmila, Hanane Saadi, Ahmed Mimouni}

Department of Obstetrics and Gynecology, Mohammed VI University Hospital, Oujda, Morocco

Received: 05 March 2020

Accepted: 30 March 2020

\section{*Correspondence:}

Dr. Hafsa Taheri,

E-mail: drtaheri.hafsa@gmail.com

Copyright: (c) the author(s), publisher and licensee Medip Academy. This is an open-access article distributed under the terms of the Creative Commons Attribution Non-Commercial License, which permits unrestricted non-commercial use, distribution, and reproduction in any medium, provided the original work is properly cited.

\begin{abstract}
Primary breast lymphoma is a primary degeneration of the breast lymphoid tissue. Study aim to describe primary breast lymphoma; its clinical presentations, histological particularities and management methods. A 33 years-old patient with no medical history underwent a breast surgery. Its anatomo-pathological study, supplemented by immunohistochemistry, showed a primary breast lymphoma. The extension assessment was negative. The patient underwent chemotherapy with regression of the tumor. Breast lymphomas are rare conditions. Its clinical symptomatology is polymorphic and the imaging aspects are non-specific. It should be evoked in front of any breast tumor in order to avoid heavy breast surgery since the basic treatment is based on chemotherapy.
\end{abstract}

Keywords: Breast, Diagnosis, Lymphoma, Primary, Treatment

\section{INTRODUCTION}

Primary breast lymphoma (PBL) is characterized by primary degeneration of the breast lymphoid tissue with or without damage to the lymph nodes in the drainage area.

In 1972, Wiseman and Liao defined PBL on the basis of three precise criteria:

- Presence of mammary glandular tissue in the middle of the lymphomatous infiltrate or in its direct contact, detected by a good quality sample.

- The absence of systemic metastases in the extension assessment.

- The absence of a history of extra mammary lymphoma.

Primary breast lymphomas represent $1.7 \%$ to $4 \%$ of extra lymph node lymphomas and less than $1 \%$ of nonHodgkin's lymphomas. ${ }^{1,2}$ There are only a hundred cases of PBL reported in the literature.
In this article, by reporting the case of a patient with diffuse large B-cell breast lymphoma, we will focus our discussion on PBL, its clinical presentations, histological particularities and management methods.

\section{CASE REPORT}

Our patient is a 33 years-old woman, with no medical history, who had a nodule of the upper medial quadrant of the right breast gradually increasing in volume.

The patient underwent a bilateral mammography showing a large multi-lobular nodular image measuring $4.5 \mathrm{~cm}$ of the right breast without suspicious microcalcifications or axillar lymphadenopathy. The ultrasound complement showed in projection of the upper medial quadrant of the right breast a large nodular hypo echogenic macro and micro lobulated image of $4.5 / 2.5 \mathrm{~cm}$ hyper vascularized, classified ACR 4, evoking a phyllode tumor (Figure 1).

A tumorectomy was performed, in a private hospital, whose anatomopathological result showed a malignant 
proliferation evoking a malignant lymphoma, or an undifferentiated carcinoma.

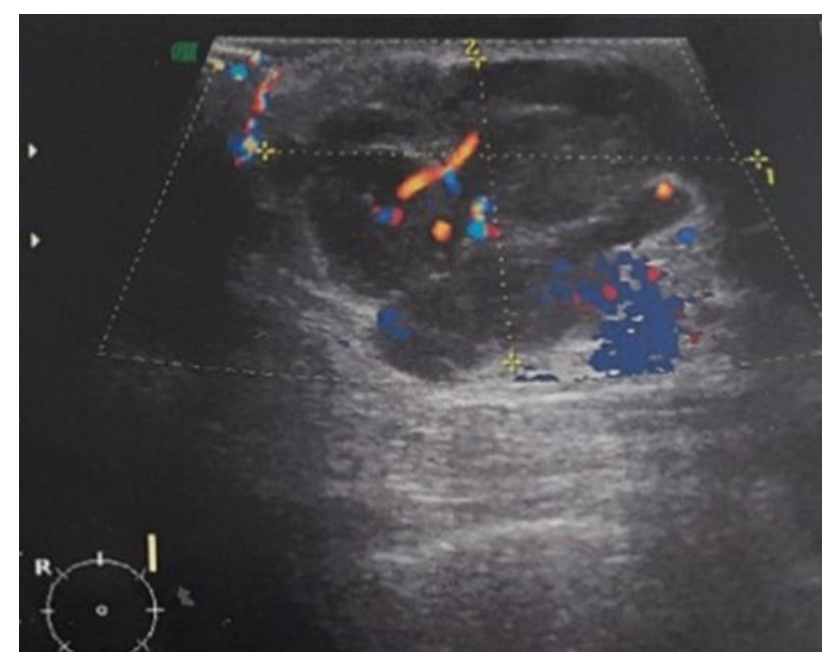

Figure 1: Breast ultrasound showing a large hyper vascularized ACR 4 tumor.

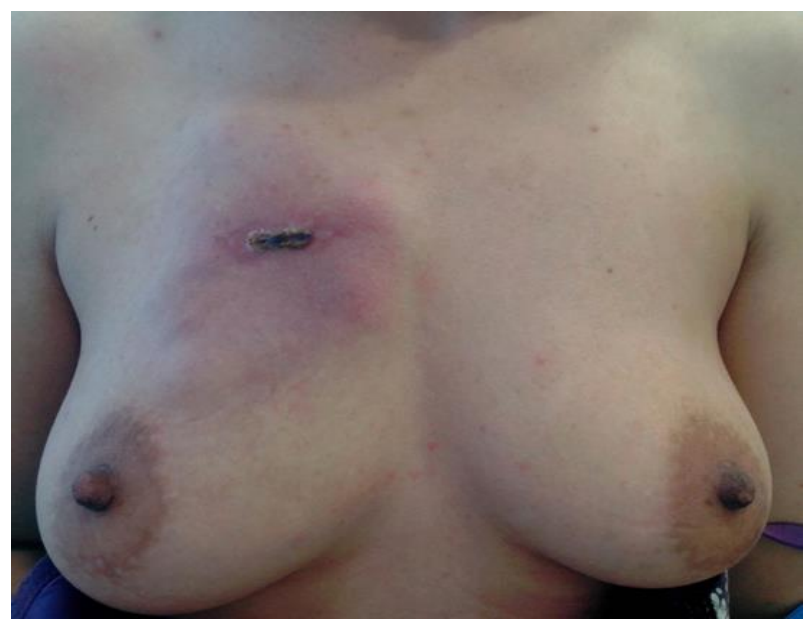

Figure 2: Front view of the inflammatory tumor of the right breast with scar from the tumorectomy.

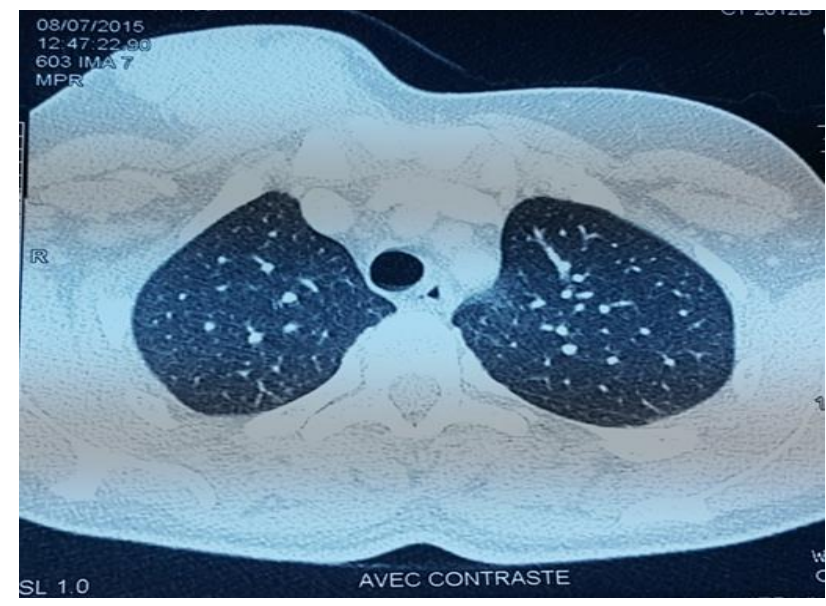

Figure 3: Chest CT scan showing a huge right breast tumor.
The immunohistochemical complement had shown that the lymphomatous cells had an intense and diffuse membrane labeling with CD20 accompanied by small lymphocyte's population of $\mathrm{T}+\mathrm{CD} 3$ phenotype. These tumoral cells did express neither CD10, BCL6 nor cyclin D1. The proliferation index Ki67 is evaluated to $80 \%$. In conclusion, this profile is that of a diffuse large B cells malignant lymphoma of the non-germinal type.

One month after the surgical intervention, the patient was referred to our hospital complaining from a polylobed nodule under the scar measuring $10 \mathrm{~cm}$, adhering to the skin associated with inflammatory signs such as redness and heat. The lymph nodes were free (Figure 2).

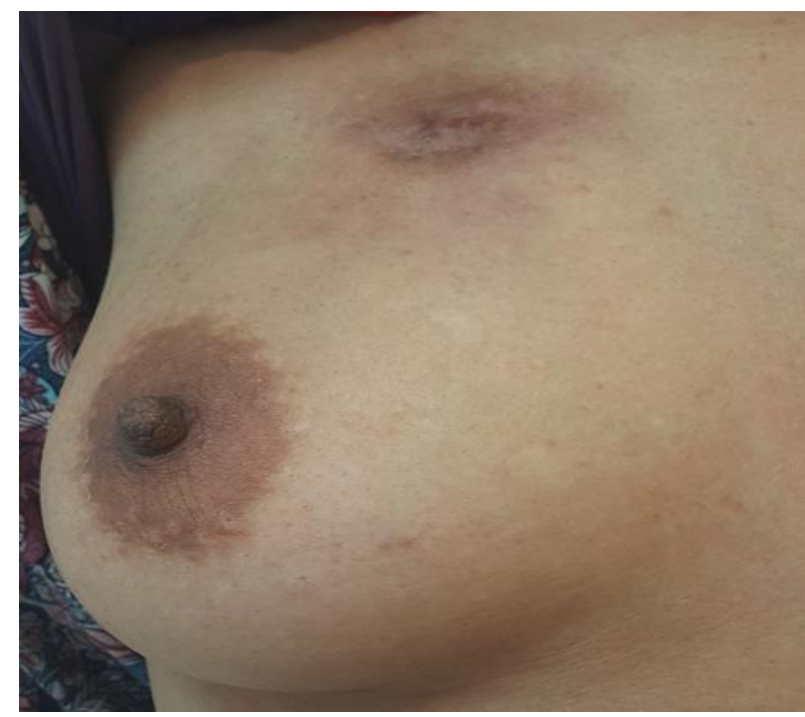

Figure 4: Clinical appearance after 4 courses of chemotherapy: total disappearance of the nodule.

Study carried out an extension assessment made of a thoraco-abdomino-pelvic CT scan which showed a right hypodense multi-lobed breast mass deforming the subcutaneous tissue of the right breast measuring 90/46/91 mm (Figure 3) with no secondary location.

The patient is currently on chemotherapy with CHOP protocol, with good progress after the $4^{\text {th }}$ cure and total disappearance of the nodule (Figure 4).

\section{DISCUSSION}

Primary breast lymphomas represent 0.04 to $0.5 \%$ of breast neoplasms, $0.7 \%$ of all lymphomas and 1.7 to $2 \%$ of primary extra-lymph node lymphomas. ${ }^{1,2}$ Their histological specificity, dominated by two subtypes, extra lymph node lymphoma from lymphoid tissue associated with the mammary mucosa (MALT lymphoma or mucosa associated lymphoid tissue) and diffuse large B-cell lymphoma. They lead to different clinical courses and different management. This type of tumor is mainly observed in women, especially the elderly. However, cases in men have been reported. ${ }^{3}$ According to the 
various series published, the average age of onset of lymphoma is between 42 and 69 years, with a peak frequency at 60 years and extreme ages from 19 to 91 years. $^{4,5}$

Few data exist on the oncogenesis of PBL. It is classic to contrast two histological forms of PBL:

- Indolent PBL, mainly with marginal zone lymphoma of MALT type.

- Aggressive lymphomas, represented by diffuse large B-cell lymphoma.

Each type of these lymphomas has different oncogenic mechanism. Rare cases of PBL with expression of hormone receptors (progestins and estrogen) by lymphomatous cells have been reported. ${ }^{1-6}$

In the group of primitive large B-cell lymphomas of the breast, certain known cytogenetic abnormalities, recurrent in these lymphomas, have been reported in $50 \%$ of cases with deregulating translocations bcl-2 [t $(12 ; 18)$, $\mathrm{t}(14 ; 18)]$, and anomalies involving bcl-6 [t $(3 ; 14)$ and $\operatorname{der}(3)(\mathrm{q} 27)]^{7}$

The most common presenting mode is a painless unilateral mass on breast examination $(60 \%$ to $100 \%$ of cases). Bilateral form represents 5 to $10 \%$ of cases. ${ }^{4,8}$

Involvement of an epsilateral axillary lymphadenopathy is observed in almost 1 of 2 cases. ${ }^{9}$ Accidental discovery on a mammography is a less frequent mode of presentation (15\%). However, neither clinical signs nor mammography allow evoking the diagnosis of lymphoma.

PBL of the diffuse large B-cell lymphoma is the most frequent type; and characterized by a greater clinical dissemination including a relapse in the central nervous system with a poor prognosis.

Radiologically, there are no specific signs that distinguish lymphoma from another malignant tumor. The lesions highlighted by mammography most often extend from a discreet well limited lesion with smooth edges and homogeneous density, of benign appearance, evoking a cyst, a fibro-adenoma or a phyllode tumor; to a diffuse hyper density of the breast parenchyma evoking mastitis with a mass of ill-defined contours or a mass with spiculated contours. ${ }^{10}$ Micro calcifications are generally absent. By ultrasound it is almost in $90 \%$ of cases oval, round, or irregular hypoechogenic masses, with posterior strengthening in $75 \%$ of cases. ${ }^{11}$ The discrepancy between a disturbing clinic and a reassuring mammographic aspect could suggest the diagnosis. ${ }^{4}$

The diagnosis is histological, and must be established by anatomopathological examination of the lesion, obtained by surgical biopsy or a micro biopsy.
The diffuse large B-cell lymphomas are most frequently observed $45 \%$ to $80 \%$, especially in the primitive forms. In this case, the activated $B$ cell phenotype (ABC) characterized by the expression of MUM-1/IRF4 and the absence of germinal center markers (Bcl 6 and CD 10) seems to be the most frequent of PBL of diffuse large Bcell lymphoma type as shown by the case of patient. ${ }^{12}$ Some have correlate it to the poor prognosis of these tumors. $^{13}$

In PBL, prognostic factors and survival vary with the histological type.

Overall, 5-year survival varies from 26 to $66 \%$ depending on the histological subtype. ${ }^{14}$ The median survival for PBL of diffuse large B-cell type is estimated to be only 36 months, making it one of the most aggressive lymphomas after lymphomas with cerebral and testicular localization.

Currently, it is well established that surgery is not part of the treatment of lymphoma and can be harmful by delaying the start of chemotherapy.

The current reference treatment is a combination of rituximab and poly chemotherapy with anthracycline (CHOP protocol). ${ }^{15}$

However, two essential features must be emphasized for these PBL with diffuse large B-cell lymphoma:

- Prophylaxis directed at the central nervous system is necessary due to a rate of cerebromeningeal relapses around 5 to $10 \%$ up to $20 \%$ in certain studies. ${ }^{16}$

- Possibility of located radiotherapy at the end of treatment at a dose of 30 to 40 Gy to reduce the risk of local recurrence and increase survival. ${ }^{17}$

\section{CONCLUSION}

PBL remains a very rare pathology. Its clinical symptomatology is polymorphic and the imaging aspect is non-specific, so it needs a histological diagnosis. It should be evoked in front of any breast tumor in order to avoid heavy breast surgery since the basic treatment is based on chemotherapy.

Funding: No funding sources Conflict of interest: None declared Ethical approval: Not required

\section{REFERENCES}

1. Hugh JC, Jackson FI, Hanson J, Poppema S. Primary breast lymphoma: an immunohistologic study of 20 new cases. Cancer. 1990;66(12):2602-11.

2. López-Guillermo A, Colomo L, Jiménez M, Bosch F, Villamor N, Arenillas L, et al. Diffuse large B-cell lymphoma: clinical and biological characterization 
and outcome according to the nodal or extranodal primary origin. J Clin Oncol. 2005;23(12):2797-804.

3. Sashiyama H, Abe Y, Miyazawa Y, Nagashima T, Hasegawa M, Okuyama K, et al. Primary nonHodgkin's lymphoma of the male breast: a case report. Breast Cancer. 1999;6:55-8.

4. Avenia N, Sanguinetti A, Cirocchi R, Bistoni G, Trastulli S, D'Ajello F, et al. Primary breast lymphomas: a multicentric experience. World J Surg Oncol. 2010;8(1):53.

5. Validire P, Capovilla M, Asselain B, Kirova Y, Goudefroye R, Plancher C, et al. Primary breast nonHodgkin's lymphoma: a large single center study of initial characteristics, natural history, and prognostic factors. Am J Hematol. 2009;84(3):133-9.

6. Hakoda Y, Gotoh A, Kuriyama Y, Kusama M, Koyanagi Y, Serizawa $H$, et al. Breast MALT lymphoma: potential relationship between hormonal environment and female sex hormone receptor expression in lymphoma cells. Leukemia Lymphoma. 2001:1157-9.

7. Niitsu $N$, Okamoto $M$, Nakamine $H$, Hirano $M$. Clinicopathologic features and treatment outcome of primary breast diffuse large B-cell lymphoma. Leukemia Res. 2008;32(12):1837-41.

8. Sokolov T, Shimonov M, Blickstein D, Nobel M, Antebi E. Primary lymphoma of the breast: unusual presentation of breast cancer. The Eur J Surg. 2000;66(5):390-3.

9. Duncan VE, Reddy VV, Jhala NC, Chhieng DC, Jhala DN. Non-Hodgkin's lymphoma of the breast: a review of 18 primary and secondary cases. Ann Diagn Pathol. 2006;10(3):144-8.

10. Cohnen M, Saleh A, Germing U, Engelbrecht V, Mödder U. Bildgebende Diagnostik supradiaphragmaler Manifestationen extranodaler Non-Hodgkin-Lymphome. Der Radiologe. 2002;42(12):960-9.
11. Lyou CY, Yang SK, Choe DH, Lee BH, Kim KH. Mammographic and sonographic findings of primary breast lymphoma. Clin Imag. 2007;1(4):234-8.

12. Talwalkar S, Miranda RN, Valbuena JR, Routbort MJ, Martin AW, Medeiros LJ. Lymphomas involving the breast: a study of 106 cases comparing localized and disseminated neoplasms. Am J Surg Pathol. 2008;32(9):1299-309.

13. Yoshida S, Nakamura N, Sasaki Y, Yoshida S, Yasuda M, Sagara H, Abe M. Primary breast diffuse large B-cell lymphoma shows a non-germinal center B-cell phenotype. Modern Pathol. 2005;18(3):398.

14. Ryan G, Martinelli G, Kuper-Hommel M, Tsang R, Pruneri G, Yuen K, et aql. Primary diffuse large Bcell lymphoma of the breast: prognostic factors and outcomes of a study by the International Extranodal Lymphoma Study Group. Ann Oncol. 2007;19(2):233-41.

15. Coiffier B, Lepage E, Brière J, Herbrecht R, Tilly H, Bouabdallah R, et al. CHOP chemotherapy plus rituximab compared with $\mathrm{CHOP}$ alone in elderly patients with diffuse large-B-cell lymphoma. N Eng J Med. 2002;346(4):235-42.

16. Ribrag V, Bibeau F, El Weshi A, Frayfer J, Fadel C, Cebotaru C, et al. Primary breast lymphoma: a report of 20 cases. Br J Haematol. 2001;115(2):253-6.

17. Avilés A, Castañeda C, Neri N, Cleto S, Nambo MJ. Rituximab and dose dense chemotherapy in primary breast lymphoma. Haematol. 2007;92(8):1147-8.

Cite this article as: Taheri $\mathrm{H}$, Hmila A, Saadi $\mathrm{H}$, Mimouni A. Primary breast lymphoma: a case report. Int J Reprod Contracept Obstet Gynecol 2020;9:2187-90. 